\title{
PERBANKAN DALAM ERA BARU DIGITAL
}

\author{
Nur Kholis \\ Dosen Program Studi Manajemen, STIE Dewantara \\ J1. Raya Pemda Bojong Depok Baru III, Karadenan, Cibinong, Bogor, Jawa Barat 16913,Indonesia \\ Email : nur.kholis@dewantara.ac.id
}

\begin{abstract}
The development of technology today was being increased rapidly to facilitate all human activities in all fields, one of them was the financial activity. During this time, the answer to the financial activity was a banking services that practice conventionally. However, with the development, emerged a new platform called Financing Technology (FinTech) which began to replace some of the bank's position in the community. Then how the future fate of banks that practice conventionally in the midst of technological developments?
\end{abstract}

Keywords: Bank, Fintech, Financing Technology.

ABSTRAK

Perkembangan teknologi saat ini semakin pesat untuk memudahkan segala aktivitas manusia dalam segala bidang, salah satunya adalah aktivitas keuangan. Selama ini, yang menjadi jawaban aktivitas keuangan adalah layanan jasa perbankan yang berpraktek secara konvensional. Akan tetapi dengan perkembangan, muncullah suatu platform baru yang dinamakan Financing Technology (FinTech) yang mulai menggantikan beberapa posisi bank di masyarakat. Lalu bagaimanakah kedepannya nasib bank yang berpraktek konvensional di tengah arus perkembangan teknologi?

Kata kunci: Bank, Fintech, Teknologi Finansial.

\section{PENDAHULUAN}

Aktivitas perbankan mulai dikenal sekitar tahun 2000 SM di Kota Asyur dan Sumeria, dimana terjadi kegiatan para pedangan yang memberikan pinjaman bijibijian kepada para petani dan pedangan yang membawa barang-barang antar-kota.

Aktivitas tersebut terus berkembang dari tahun ke tahun hingga tiba di bumi Indonesia yang saat itu masa dalam masa penjajahan Hindia Belanda. Dan saat ini, perbankan sudah tersebar sampai pelosok pedesaaan.

Jasa perbankan sangat penting dalam pembangunan ekonomi suatu negara. Dimana perbankan memiliki setidaknya dua tujuan. Pertama sebagai jasa penyedia mekanisme dan alat pembayaran yang efisien bagi nasabah. Dan yang kedua adalah dengan menerima tabungan dari nasabah dan meminjamkannya kepada pihak yang membutuhkan dana, yang dapat diartikan bahwa bank dapat meningkatkan arus dana untuk investasi dan pemanfaatan yang lebih produktif.

Bisnis perbankan adalah bisnis layanan atau jasa. Dimana, core-business perbankan adalah mengumpulkan dana dari masyarakat (funding), kemudian menyalurkan dana kepada masyarakat yang membutuhkan (financing/ lending) dan memberikan jasa layanan perbankan (banking service).

Perbankan adalah bisnis yang padat karya, yakni yang dapat menyerap banyak tenaga kerja. Semisalkan seseorang datang ke sesuatu cabang sebuah bank, misalnya untuk menabung. Saat membuka pintu bank tersebut, sudah dapat dijumpai orangorang yang bekerja memberikan layanan salah satu core business nya yaitu layanan funding, atau pengumpulan dana dari masyarakat. Di dalam banking hall, tersebut dapat dijumpai customer service yang dengan ramah melayani kebutuhan perbankan nasabah seperti pembukaan 
rekening, deposito dan lainnya. Kemudian ada teller, yang melayani setoran tunai, tarikan tunai, transfer dan lainnya. Dan banyak lagi, yang bekerja di back office, yang menjalankan dan memenuhi kebutuhan transaksi perbankan nasabah.

Kemudian apabila nasabah datang ke bank, untuk mendapatkan pinjaman, nasabah dapat menjumpai account manager yang dengan sabar dan cermat mendengarkan kebutuhan nasabah, kemudian memberikan solusi atas kebutuhan nasabah tersebut. Dan nasabah pun sebagai nasabah, dimanjakan dengan fasilitas-fasilitas yang disediakan oleh bank, seperti Anjungan Teller Mandiri (ATM), mobile banking, internet banking, sms banking, dan lain-lain.

Seiring perkembangan teknologi, digital banking mulai mewarnai setiap aktivitas keuangan nasabah. Kemudahan yang diberikan membuat nasabah merasa diuntungkan. Namun sayangnya, layanan perbankan digital ini masih dinikmati oleh sebagian masyarakat Indonesia. Berdasarkan data dari lembaga keuangan dunia menyatakan hanya $54 \%$ dari masyarakat Indonesia yang tersentuh layanan perbankan dan selebihnya belum.

Generasi millenial sekarang berfikir bahwa ATM, mobile banking, internet banking, sms banking dan lain-lainnya adalah sudah biasa, alias mainstream. Sekarang masyarakat berfikir, bagaimana masyarakat ingin membuka rekening, menabung, mengajukan kredit atau pinjaman dan layanan perbankan lainnya, tanpa harus menghadirkan diri secara fisik di bank bersangkutan.

Hal inilah yang ditangkap sebagai potensi dan kesempatan oleh bank, untuk meningkatkan minat calon nasabah menjadi nasabah di bank, memberikan layanan yang nasabah inginkan sehingga loyal terhadap bank.

Sepertinya ini, semua sudah dimulai oleh beberapa bank. Akan tetapi sebelum membahasnya, mari lihat dampak yang akan terjadi terhadap transaksi perbankan secara konvesional yang merupakan industri padat karya.

Dari beberapa hal tersebut, masalah pokok paper ini antara lain :

a. Bagaimanakah kelanjutan SDM yang selama ini bekerja di layanan perbankan seperti customer service, teller dan lainnya, apabila fungsinya sudah digantikan dengan digital application?

b. Bagaimanakah keamanan transaksi nasabah, apabila semua layanan dilakukan secara digital, tanpa harus ada kehadiran fisik nasabah di kantor cabang bank bersangkutan?

c. Bagaimanakah regulasi yang diberikan oleh Bank Indonesia dan Otoritas Jasa Keuangan terhadap layanan perbankan secara digital tersebut?

\section{TINJAUAN PUSTAKA}

Menurut UU No. 7 tahun 1992 tentang Perbankan, sebagaimana telah diubah dengan UU No. 10 tahun 1998, yang dimaksud dengan Bank adalah badan usaha yang menghimpun dana dari masyarakat dalam bentuk simpanan, dan menyalurkannya kepada masyarakat dalam bentuk kredit dan atau bentuk-bentuk lainnya, dalam rangka meningkatkan taraf hidup masyarakat banyak.

Definisi diatas memberikan penekanan bahwa usaha utama bank adalah menghimpun dana dalam bentuk simpanan yang merupakan sumber dana bank. Demikian pula dari segi penyaluran dana, hendaknya bank tidak semata-mata memperoleh keuntungan yang sebesarbesarnya bagi pemilik, tapi juga kegiatannya harus pula diarahkan pada peningkatan taraf hidup masyarakat.

Resiko-resiko yang dihadapi oleh bank antara lain resiko : kredit, investasi, likuiditas, operasional, penyelewengan, fidusia, tingkat bunga, solvensi, valuta asing dan persaingan. Sehingga memaksa 
Bank untuk memiliki Standard of Procedure (SOP) yang jelas untuk dapat memitigasi resiko yang mungkin timbul.

Contohnya dalam hal pemberian kredit atau pembiayaan, menurut Jopie Yusuf dikenal adanya prinsip 5C yakni : Character, Capacity, Capital, Condition dan Collateral. Bahkan ditambahkan lagi dengan prinsip 7P yakni : Personality, Party, Purpose, Prospect, Payment, Profitability dan Protection.

Seiring berjalannya waktu, teknologi berevolusi mengikuti perkembangan manusia itu sendiri. Dari waktu ke waktu, manusia ingin mendapatkan hal-hal yang mudah untuk memuaskan segala keinginannya. Mulai dari bangun tidur hingga tidur lagi, manusia ingin segala aktivitasnya terlaksana sesuai dengan rencananya dan tentunya dengan kemudahan-kemudahan yang didapatkan. Saat ini, apabila ingin bepergian ke suatu daerah manusia tinggal menggunakan aplikasi digital yang ada di genggamannya, ingin makan, tinggal klik, dan lain sebagainya.

Lambat laun, hal tersebut merambah ke sektor perbankan. Dan dimulai sejak tahun 2015, masyarakat mulai mengenal FinTech. FinTech sendiri merupakan singkatan dari Financing Technology atau dalam bahasa Indonesia dikenal dengan Teknologi Finansial. Hampir semua bank sudah menggunakan teknologi finansial di aplikasi layanannya, yang dikenal dengan mobile banking, internet banking, dan lainnya.

\section{METODE PENELITIAN}

Jenis metodologi penelitian yang digunakan adalah deskriptif kualitatif, yang menggambarkan fenomena perkembangan teknologi yang berkembang dewasa ini. Yang memberikan uraian mengenai gejala sosial yang diteliti yakni perkembangan teknologi keuangan terhadap layanan perbankan yang selama ini berpraktek secara konvensional.
Data-data yang dipakai adalaah berupa literatur, berita-berita, wawancara dan pengamatan langsung dengan apa yang terjadi di dalam teknologi keuangan yang semakin berkembang pesat, dengan memperhatikan regulasi-regulasi yang diberlakukan oleh pihak regulator yakni Bank Indonesia dan Otoritas Jasa Keuangan.

\section{HASIL DAN PEMBAHASAN}

Berdasarkan jurnal yang membahas pengaruh kualitas layanan, kepuasan nasabah dan citra bank terhadap loyalitas layanan, dikatakan bahwa produk perbankan harus memiliki keunggulan sehingga menciptakan permintaan yang tinggi dari nasabah. Kemudian harus memberikan layanan yang optimal agar nasabah merasa aman, nyaman dan mudah dalam melakukan transaksi perbankan.

Layanan perbankan ini dimulai dari petugas frontliner seperti petugas satuan pengamanan, customer service, teller dan penerima telepon yang skillnya dapat mengikuti perkembangan ekspektasi nasabah yang terus meningkat.

Dan ternyata itu dapat membuktikan bahwa adanya pengaruh dari kualitas layanan suatu bank terhadap loyalitas nasabah perbankan. Loyalitas tersebut dapat berbentuk tingginya keinginan masyarakat untuk tetap menjadi nasabah atau mendapatkan banyak nasabah baru.

Sekitar tahun 1980-an, bank mulai menggunakan sistem pencatatan data yang bisa diakses dengan computer. Dan inilah yang sebenarnya menjadi embrio berkembangnya fintech yang mulai muncul di dalam back office layanan perbankan serta fasilitas permodalan lainnya.

Dan ditahun 1998 perbankan mulai mengenalkan layanan online banking untuk para nasabahnya. Fintech pun menjadi semakin mudah digunakan masyarakat luas

Cikal bakal revolusi digital dimulai dengan ditemukannya komputer, yang beberapa tahun kemudian yakni sekitar 
tahun 1992, hampir di setiap negara memiliki akses jaringan/ internet untuk memudahkan segala aktivitas, baik sosial maupun bisnis dan lainnya. Dan loncat ke tahun 2000-an muncullah situs jejaring sosial atau sosial media. Hingga tak salah, ada yang menyebut generasi sekarang, atau generasi millenial adalah generasi amnesia. Kenapa dikatakan amnesia, karena hampir di setiap kegiatan, selalu ditemani oleh smartphone. Berjalan sambil melihat smartphone, makan dengan smartphone, bahkan ke kamar mandi pun ditemani oleh smarphone. Hingga saat bercengkrama dengan teman maupun keluarga pun sambil melihat smartphone, sehingga tak ayal, tidak saling bertegur sapa ataupun berbincang hangat dengan kolega, seperti zaman dahulu.

Bersandar pada publikasi yang disampaikan oleh www.wearesocial.com yang menyampaikan data bahwa :

a. Lebih dari setengah populasi dunia menggunakan smartphone.

b. Hampir 2/3 dari populasi dunia memiliki mobile phone/ hand phone.

c. Lebih dari setengah lalu lintas data digital/ internet, diakses dengan mobile phone dan smartphone.

d. Lebih dari 1/5 dari populasi dunia berbelanja dengan online shoppping.

Berikut adalah gambaran global yang disampaikan oleh www.wearesocial.com, yang menyatakan perkembangan dunia digital meningkat secara spektakuler, dimana meningkat secara tajam dibanding tahun sebelumnya.

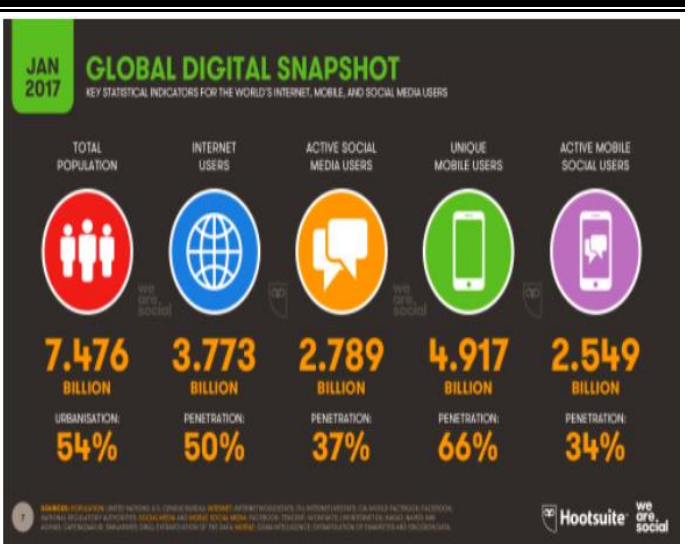

Masih berdasarkan data dari www.wearesocial.com, Indonesia dengan total populasi yang mencapai 262 juta jiwa ada 132.7 juta yang aktif menggunakan internet, ini berarti ada peningkatan sebesar $51 \%$ jika dibandingkan pada tahun lalu. Tentunya masih didominasi oleh pengguna mobile.

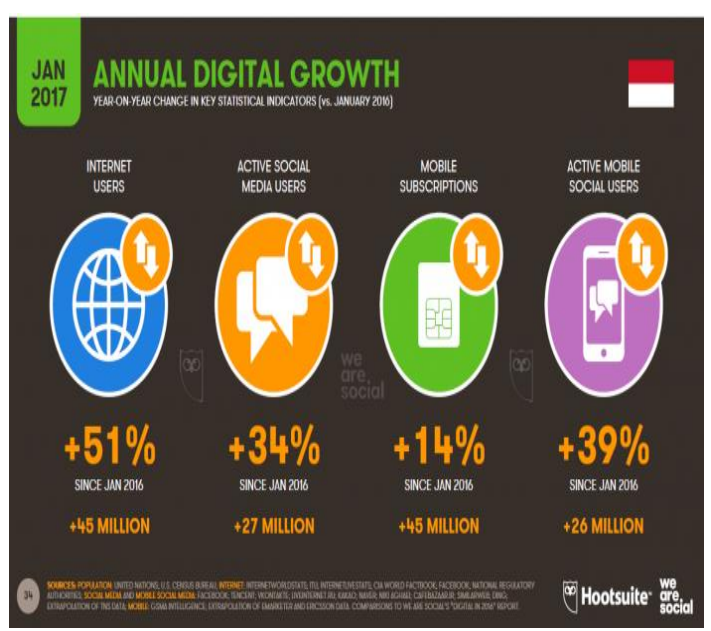

Layanan keuangan berbasis teknologi digital saat ini berkembang pesat sejalan dengan kemajuan teknologi digital. Bank pun mulai beralih dari mengandalkan kantor dan layanan konvensional ke layanan aplikasi digital. Ini merupakan sebuah transformasi atau perubahan yang tidak dapat dielakkan di era sekarang.

Perbankan perlu aware atau memberikan perhatian terhadap perkembangan teknologi digital tersebut, jika tidak ingin ditinggalkan nasabahnasabahnya yang beralih kepada lembaga keuangan yang memanjakan keinginan nasabah. 
Contoh layanan perbankan yang melakukan transformasi adalah dengan apa yang dilakukan oleh Bank BTPN melalui produknya yang dinamakan "BTPN Jenius" dan "BTPN Wow !". Dan saat ini sudah diikuti oleh beberapa Bank lainnya, seperti BCA, BNI, dan lain-lain.

PT Bank Tabungan Pensiunan Nasional Tbk (BTPN) terus melakukan inovasi dalam produk dan layanan agar relevan dengan masyarakat penggunanya. Terutama dalam inovasi dan pengembangan produk dan layanan digital. Sepanjang sembilan bulan pertama 2017, perseroan telah menanamkan investasi Rp 624 miliar atau meningkat 77 perseroan dibandingkan nilai investasi di periode sama tahun sebelumnya.

Saat ini BTPN memiliki dua platform digital banking untuk melayani dua segmen yang berbeda. Pertama BTPN Wow! yang diperuntukkan bagi kelompok masyarakat menengah ke bawah dan kedua platform Jenius untuk segmen consuming-class.

Era digital membawa aura baru persaingan di industri perbankan. Namun, tak semua bank siap menghadapinya. Sebut saja bank kecil, seperti bank BUKU I dan bank BUKU II.

\section{Regulatory sandbox scheme}

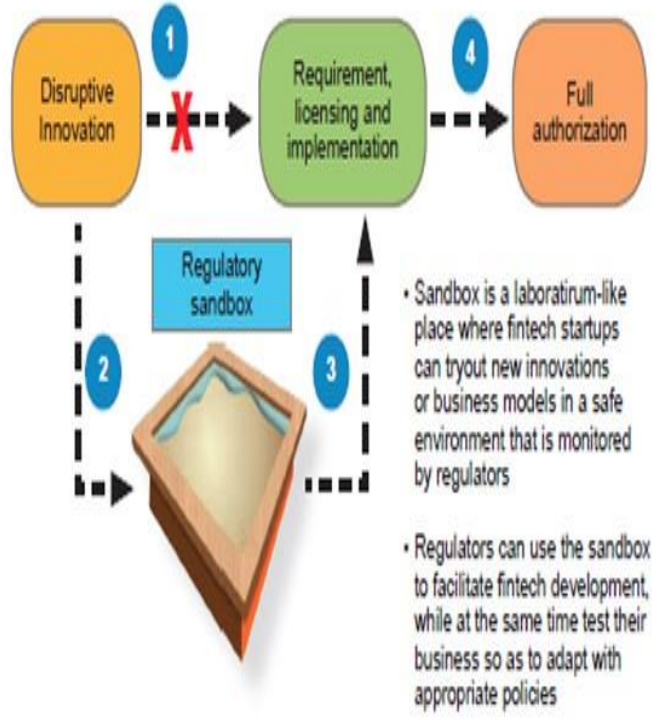

Soutce: Bsakk Indonesis
Dari laman www.infobanknews.com yang berjudul "Ini Penyebab Bank BUKU II Kesulitan Transformasi ke Digital", Menurut A. Prasetyantoko, Ekonom yang juga menjabat juga sebagai rektor Universitas Katholik Atmajaya, bank BUKU II banyak yang secara financial sanggup perkuat IT, namun untuk SDM yang dibutuhkan untuk bisa mendukung itu belum banyak, dan bank konvensional memiliki mitigasi resiko yang cukup ketat.

Dan dari laman www.infobanknews.com yang berjudul "Jenius" Jadi Bukti Bank Mulai Tranformasi Layanan", menurut Adrian A. Gunadi, CEO Investree, perusahaan yang bergerak di dalam bisnis FinTech (Financial Technology), bahwa kriteria mitigasi resiko di FinTech dan perbankan konvensional saat ini sangat berbeda. Di era digital saat ini, nasabah membutuhkan kecepatan proses, dan efisiensi, sehingga lembaga yang berbasis FinTech melakukan mitigasi resiko seperti layaknya bank konvensional. Di dalam FinTech sendiri, mempunyai standar prosedur sendiri dalam melakukan mitigasi resiko.

Sejarah FinTech sendiri dimulai di bulan Maret 2015 dengan diadakannya pertemuan komunitas FinTech, yang mengambil keputusan untuk diluncurkannya secara resmi di publik pada bulan September 2015. Dan untuk memenuhi regulasi dari Pihak Otoritas diadakanlah pertemuan dengan Ketua Dewan Komisioner Otoritas Jasa Keuangan (OJK) pada Oktober 2015 dan dimulailah sesi rutin dwi-mingguan. Walhasil, pada Maret 2016, FinTech secara resmi menjadi Badan Hukum perkumpulan dan terdaftar Kementerian Hukum dan HAM Republik Indonesia. Dan mulai bulan Mei tahun 2016, FinTech membuka pendaftaran keanggotaan kepada publik. Dan bulan Juli 2016, diadakan pertemuan dengan Gubernur Bank Indonesia (BI) dan memulai sesi rutin dengan $\mathrm{BI}$, dan terus 
berkelanjutan hingga September 2016, FinTech aktif bermitra dengan OJK dan BI dan seluruh lembaga pemerintahan lainnya dalam mengembangkan kebijakan FinTech di Indonesia, dengan dikeluarkannya Peraturan Otoritas Jasa Keuangan Nomor 77/POJK.01/2016 tentang Layanan Pinjam Meminjam Uang Berbasis Teknologi Informasi.

Dan pada tanggal 30 November 2017, Bank Indonesia mengeluarkan Peraturan Anggota Dewan Gubernur Nomor 19/14/PADG/2017 tentang Ruang Uji Terbatas (Regulatory Sandbox) Teknologi Finansial, dimana Regulatory Sandbox didefinisikan sebagai suatu ruang uji terbatas yang aman untuk menguji Penyelenggara Teknologi Finansial beserta produk, layanan, teknologi, dan/ atau model bisnisnya.

Perusahaan FinTech yang masuk ke dalam Regulatory Sandbox, berkewajiban untuk memastikan dilakukannya prinsip perlindungan konsumen, manajemen risiko dan kehati-hatian yang memadai. Perusahaan tersebut wajib menyampaikan laporan pelaksanaan uji coba, baik secara reguler maupun insentif sesuai dengan permintaan BI, serta menaati ketentuan peraturan perundang-undangan.

Adapun tanggung jawabnya kepada BI, perusahaan FinTech tersebut harus memberikan kebenaran dan keakuratan data, informasi, dan dokumen yang disampaikan. Keamanan dan keandalan sistem yang digunakan untuk menjalankan produk, layanan, teknologi, dan/atau model bisnis yang diuji coba dalam Regulatory Sandbox.

Selama pelaksanaan uji coba dalam Regulatory Sandbox, BI melakukan pendampingan dan review sebagai dasar untuk menetapkan status hasil uji coba penyelenggara Teknologi Financial. Jangka waktu uji coba ditetapkan paling lama enam bulan namun bila diperlukan dapat diperpanjang $1 \mathrm{x}$ paling lama enam bulan.

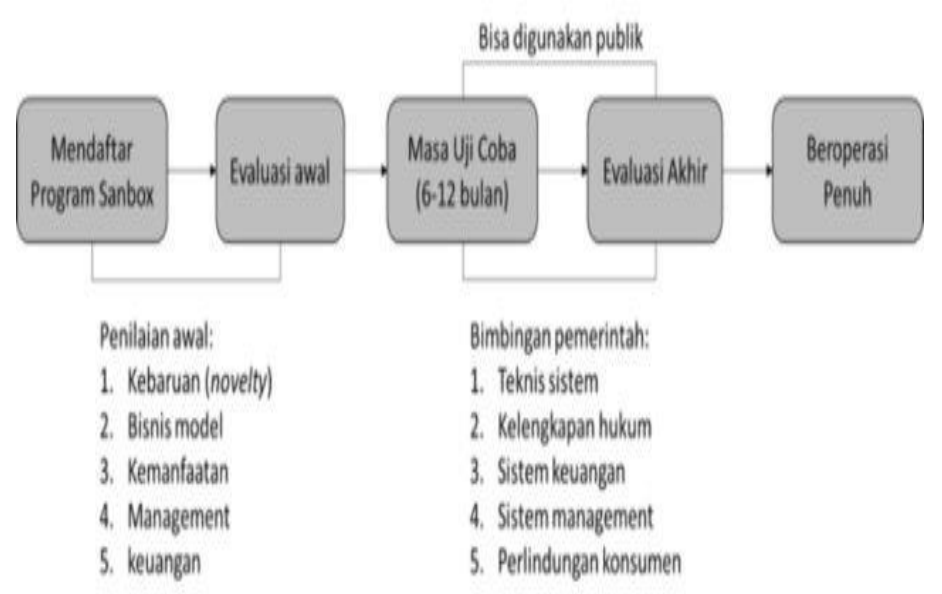

Setelah jangka waktu uji coba habis selama enam bulan, BI akan menetapkan status hasil uji coba berdasarkan penilaian atas seluruh rangkaian kegiatan. Status hasil uji coba tersebut terdiri dari tiga, yaitu berhasil, tidak berhasil, dan status lain yang ditetapkan BI.

Apabila berhasil, dapat dilanjutkan dengan proses perizinan. Namun bila tidak berhasil, dilarang untuk memasarkan produknya.

Apabila ada perusahaan lainnya yang sudah terdaftar di BI dan bisa memenuhi kriteria untuk masuk ke regulatory sandbox, maka akan masuk dalam radar BI berikutnya.

Diharapkan ketentuan tersebut dapat mendorong ekosistem FinTech yang sehat untuk mendukung pertumbuhan ekonomi nasional yang berkelanjutan dan inklusif, dengan tetap menjaga stabilitas moneter, stabilitas sistem keuangan, serta sistem pembayaran yang efisien, lancar, aman, dan andal.

Kunci utama dari keberhasilan sistem Regulatory Sandbox terletak pada pendampingan pemerintah. Oleh sebab itu, Regulatory Sandbox hanyalah sebuah nama program yang bertujuan untuk mengembangkan perusahaan-perusahaan FinTech. Melalui pendampingan hukum dan pendampingan teknis, maka FinTech akan teruji sebelum beroperasi di masyarakat. Setelah pendampingan kemudian pemerintah menetapkan ijin operasional dan standar pelayanan. Tujuan 
utama dari program Regulatory Sandbox adalah mendapat kepercayaan publik bahwa FinTech yang lahir itu akan aman dalam beroperasi. Dengan adanya kepercayaan masyarakat maka tentunya pengguna akan lebih banyak. Ini menunjukkan bahwa instrumen hukum keuangan Inggris dirancang sedemikian rupa dengan berorientasi kepada pasar (marketoriented). Meski berorientasi pada pasar tentunya secara nasionalisme juga tetap dijaga keseimbangannya, yaitu dengan menjaga agar industri keuangannya tetap kuat untuk berkompetisi. Secara umum, program sandbox dapat digambarkan sebagai berikut.

FinTech hadir di Indonesia sebagai wadah yang menghimpun perusahaan dan institusi para pelaku sektor jasa keuangan yang menggunakan kemajuan teknologi dalam menjalankan usahanya,

Saat ini FinTech sendiri sudah memiliki banyak member yang terdiri dari 103 perusahaan Startup, 22 Lembaga Keuangan dan 7 Mitra Asosiasi, seperti kartuku, Midtrans, Doku, Bareksa, cekaja.com, Modalku, BCA, DBS, BTPN, Bank Danamon, CIMB Niaga, Deloitte, Mc.Kinsey dan masih banyak lainnya.

Selama ini FinTech memiliki image destruktif atau menghancurkan terhadap bisnis perbankan. Padahal usaha FinTech dibentuk guna memberikan solusi bagi masyarakat, bukan merusak usaha. Bank tidak perlu merasa terancam karena usaha FinTech justru akan melebarkan jaringan layanan perbankan, yang tentunya hal ini akan berdampak positif bagi Indonesia, dimana penetrasi produk keuangan relatif rendah.

Di surat kabar "The Jakarta Post" edisi 21 November 2017, dengan headline yang berbunyi "The "banking versus fintech' myth : collaboration, not competition", Reynold Wijaya yang merupakan Koordinator Satgas Peer to Peer $(P 2 P)$ Lending Asosiasi Fintech
Indonesia dan CEO \& Co-Founder Modalku, mengatakan :

"Synergy between fintech and the banking sector is a quintessential key for financial inclusion to empower the country's economy. The Peer to Peer (P2P) Lending business model, one that Modalku adopts, is not the same with the banking sector and similarity between their products are limited - by nature, however, both sectors complement one another. Regardless of fintech's presence, technological developments such as artificial intelligence and automation will eliminate certain conventional functions. It is not fintech that will erode the existence of the banking sector"

FinTech, bersinergi dengan perbankan, sesungguhnya menjadi kunci bagi inklusi keuangan untuk penguatan ekonomi nasional. Model bisnis platform Peer to Peer (P2P) lending seperti misalnya Modalku, tidak sama dengan perbankan dan keduanya hanya memiliki kesamaan produk yang terbatas, namun demikian sejatinya saling melengkapi. Perkembangan teknologi, seperti artificial intelligence dan automation, dapat menghilangkan sebagian pekerjaan yang dahulu dilakukan secara konvensional terlepas dari keberadaan FinTech, bukan berarti layanan FinTech kemudian akan menggerus bank.

Meski perbankan dan Peer to Peer $(P 2 P) \quad$ Lending selintas tampak menawarkan layanan yang sama, namun sebenarnya terdapat perbedaan mendasar di antara keduanya.

Pertama; suku bunga. Layanan Peer to Peer (P2P) Lending yang umumnya menawarkan pinjaman tanpa agunan dan menyasar segmen yang lebih berisiko, secara natural akan menawarkan suku bunga yang lebih tinggi. Oleh sebab itu segmen yang sudah bankable umumnya akan memilih pinjaman dari bank ketimbang dari platform ini.

Kedua; periode tenor pengembalian pinjaman. Layanan Peer to Peer $(P 2 P)$ 
Lending di Indonesia biasanya menerapkan tenor yang relatif pendek sekitar 1 hingga 24 bulan, karena tenor yang panjang akan mengurangi minat pemberi pinjaman dan menambah risiko pinjaman tanpa agunan. Sebaliknya, perbankan lebih suka menawarkan tenor panjang untuk mengoptimalkan net interest margins.

Ketiga; besarnya jumlah pinjaman. Layanan Peer to Peer $(P 2 P)$ Lending nyaris tidak mungkin memberikan pinjaman dengan jumlah yang sangat besar misalnya puluhan atau ratusan miliar. Diperlukan begitu banyak pemberi pinjaman sehingga dapat menunda pencairan pinjaman.

Sebaliknya, kekuatan perbankan untuk memberikan pinjaman dengan nilai tinggi tidak diragukan lagi dan dapat dilakukan secara cepat dan murah sehingga tidak mungkin Peer to Peer (P2P) Lending dapat bersaing dengan ini.

Perbedaan-perbedaan di atas menunjukan bahwa persepsi adanya persaingan sengit antara perbankan dan Peer to Peer $(P 2 P)$ Lending adalah salah. Kedua industri ini justru komplementer bila berkolaborasi. Sinergi FinTech dan bank dapat dibandingkan dengan low cost airlines dan full service airlines yang jelas melayani segmen pasar yang berbeda, namun keduanya bertumbuh beriringan dan memajukan perekonomian Indonesia.

Dari pembahasan diatas maka perbankan dan FinTech dapat bersinergi, berkolaborasi dalam memberikan layanan kepada seluruh lapisan masyarakat dengan segmen pasar yang berbeda. Sehingga berdirinya perbankan dan layanan perbankan tetap dibutuhkan oleh masyarakat.

Dan secara regulasi, pemerintah telah mengaturnya, salah satunya dengan menerapkan mekanisme Regulatory Sandbox sebelum mendapatkan pengesahan izin dari Bank Indonesia.

\section{KESIMPULAN DAN SARAN}

\subsection{Kesimpulan}

Berdasarkan pembahasan diatas dapat dikatakan bahwa perkembangan teknologi memang tak dapat dibendung perkembangannya, dimana perkembangannya tersebut berbanding lurus dengan keinginan manusia sendiri untuk mendapatkan kemudahan di setiap aktivitasnya. Salah satunya aktivitas keuangan, yang kesehariannya bersinggungan langsung dengan layanan perbankan.

Layanan perbankan konvensional memang membutuhkan cost yang tinggi, investasi yang cukup besar. Namun dengan berkembangnya teknologi, hal itu semua dapat dipangkas dengan FinTech. Awalnya, banyak yang berpersepsi bahwa FinTech akan mengganti posisi bank di dunia perekonomian. Akan tetapi saat ini, kehadiran FinTech belum bisa menggantikan posisi bank, bahkan berjalan berdampingan sehingga kemajuan ekonomi dapat dilakukan bersama.

Dan sebagai regulator, Bank Indonesia dan Otoritas Jasa Keuangan pun sudah menerapkan aturan yang jelas dan tegas dengan dikeluarkannya Peraturan Otoritas Jasa Keuangan Nomor 77/POJK.01/2016 tentang Layanan Pinjam Meminjam Uang Berbasis Teknologi Informasi, yang mengatur segala hal untuk melindungi kepentingan masyarakat baik sebagai pemberi pinjaman ataupun peminjam.

Dan pada tanggal 30 November 2017, Bank Indonesia mengeluarkan Peraturan Anggota Dewan Gubernur Nomor 19/14/PADG/2017 tentang Ruang Uji Terbatas (Regulatory Sandbox) Teknologi Finansial, dimana Regulatory Sandbox didefinisikan sebagai suatu ruang uji terbatas yang aman untuk menguji Penyelenggara Teknologi Finansial beserta produk, layanan, teknologi dan/ atau model bisnisnya. 


\subsection{Saran}

Perkembangan teknologi yang tak dapat dibendung memunculkan evolusievolusi untuk dapat memudahkan manusia dan memuaskan keinginannya dalam segala aktivitasnya. Dan ini seharusnya menjadi lampu kuning bagi setiap usaha, khususnya untuk perbankan, untuk meningkatkan kemampuannya, baik dari segi sumber daya manusia maupun sumber daya teknologinya, sehingga tetap eksis melayani masyarakat.

\section{DAFTAR PUSTAKA}

Satriyanti, Evi Oktaviani. 2012. Journal of Business Banking :"Pengaruh Kualitas Layanan, Kepuasan Nasabah dan Citra Bank Terhada Loyalitas Nasabah Bank Muamalat di Surabaya"

Iman, Nofie. 2016. Financial Technology dan Lembaga Keuangan. Gathering Mitra Linkage Bank Syariah Mandiri.

Pratama, Bambang. 2016. Mengenal Regulatory Sandbox pada FinTech. http://businesslaw.binus.ac.id/2016/09/29/mengenalregulatory-sanbox-pada-fintech/

Jusuf, Jopie. 2010. Analisis Kredit untuk Account Officer. Edisi Kesebelas. PT. Ikrar Mandiri Abadi, Jakarta.

Wijaya, Reynold. 2017. The Jakarta Post : "The Banking vs Fintech Myth : Collaboration, Not Competition. Terbit tanggal 21 November 2017

Otoritas Jasa Keuangan. 2016. POJK No. 77/POJK.01/2016 tentang Layanan Pinjam Meminjam Uang Berbasis Teknologi Informasi.

Bank Indonesia, 2016. PADG No. 19/14/PADG/2017 tentang Ruang Uji Terbatas (Regulatory Sandbox) Teknologi Finansial.

https://id.wikipedia.org/wiki/Revolusi_Digi tal. (Diakses tanggal 5 November 2017). https://www.kompasiana.com/reza_hermaw anyadi/data-menarik-mengenai-duniadigital-indonesia2017_58d4d4963297736e24f32cfc. (Diakses tanggal 5 November 2017).

https://id.techinasia.com/potensi-digital marketing-indonesia-di-tahun-2017. (Diakses tanggal 5 November 2017).

http://batam.tribunnews.com/2016/01/15/pe rkembangan-dunia-digital-indonesiaberdampak-besar-pada-ekonomi-lokaldan-dunia. (Diakses tanggal 5 November 2017).

https://katadata.co.id/telaah/2016/03/01/dun ia-digital-yang-mengubah-modelbisnis-di-indonesia. (Diakses tanggal 5 November 2017).

https://wearesocial.com/specialreports/digital-in-2017-globaloverview. (Diakses tanggal 5 November 2017).

https://www.kompasiana.com/kelompok5to p/5a0272ae9b1e67146d033532/masadepan-industri-keuangan-perbankandi-era-digital-ekonomi. (Diakses tanggal 5 November 2017).

http://ekonomi.kompas.com/read/2017/04/1 8/210000426/bisnis.model.baru.bank.fintech.dan.ekonomi.digital. (Diakses tanggal 5 November 2017).

http://infobanknews.com/tag/digitalbanking/. (Diakses tanggal 5 November 2017).

http://marketeers.com/masa-depanperbankan-ada-di-digital-banking/. (Diakses tanggal 5 November 2017). http://marketeers.com/masa-depanperbankan-ada-di-digital-banking/. (Diakses tanggal 5 November 2017). http://infobanknews.com/tag/digital-

banking/. (Diakses tanggal 5 November 2017).

http://ekonomi.kompas.com/read/2017/10/2 7/162200026/digitalisasi-itu-kekinianbahkan-dalam-berasuransi. (Diakses tanggal 5 November 2017). 